\title{
La herida colonial y la cultura revolucionaria: leer a Roque Dalton
}

Roberto Herrera ZÚNíga

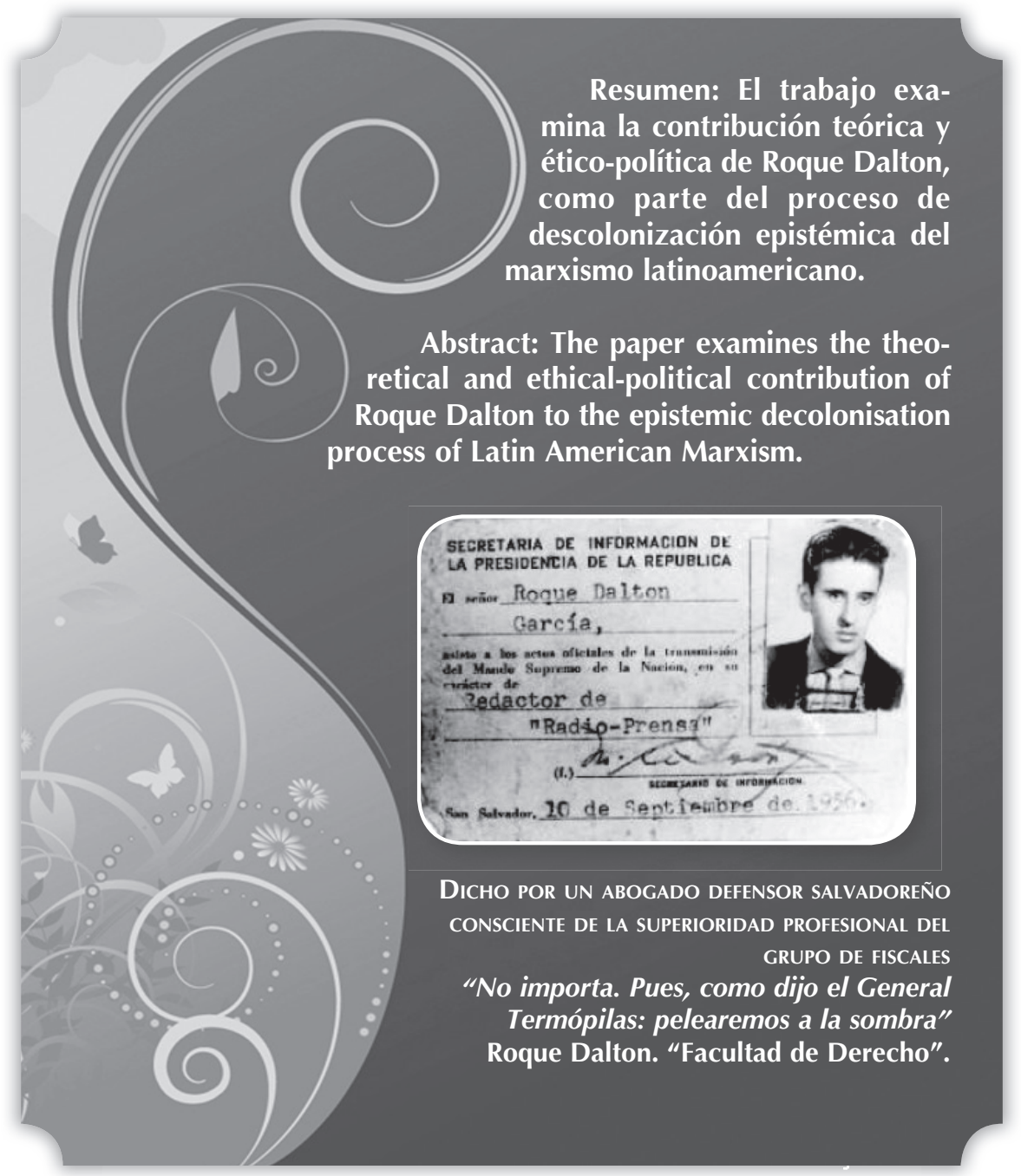




\section{Introducción}

$\mathrm{E}$

ste texto es la versión parcialmente corregida y modificada de una comunicación que leímos en el Coloquio-Recital en homenaje a Roque Dalton, organizado por la Asociación de Estudiantes de Filosofía de la Universidad de Costa Rica, el jueves 1 de Octubre de 2009.

Como señalamos en el evento y como se muestra en el epígrafe, este texto no es más que una "pelea de sombras". La obra de Dalton tiene una potencialidad y una variabilidad de sentidos y posibilidades que hace sentir, desde un primer momento, que estamos en presencia de una obra la cual sobrepasa las capacidades interpretativas propias. Aquí presentamos solo unos pocos aspectos de su obra y una línea de interpretación que estimamos podría colaborar a abrir un nuevo campo para entender el significado y la actualidad del daltonismo en América Latina.

\section{La lógica daltónica}

Con el libro Introducción a Lógica de Luis Camacho aprendimos que la categoría escolástica quaternio terminorum consiste: "en tener en realidad cuatro términos (...) donde a simple vista aparecen solo tres" (115). Así, si afirmamos que: "Sin retórica no hay comunicación. Pero la retórica es palabrería vana. Por lo tanto sin palabrería vana no hay comunicación" (115) estaría incurriendo en este tipo de falacia.

Antes de conocer el significado de esta categoría escolástica, habíamos leído que "es en la práctica donde el hombre tiene que demostrar la verdad, es decir, la realidad y el poderío, la terrenalidad de su pensamiento. El litigio sobre la realidad o irrealidad de un pensamiento que se aísla de la práctica, es un problema puramente escolástico." (Marx, 1978, 666).

Una hipótesis plausible es que Roque Dalton, producto de su militante e irreverente anticlericalismo y su seguro conocimiento de la Tesis II, decidió no dar tregua a la escolástica ni siquiera en el terreno de la lógica.

Explicamos en detalle. Michael Löwy, en su polémica contra el positivismo durkheimiano, señala: "Durkheim, como buen positivista cree que los "prejuicios" y las "prenociones" pueden ser "desechadas" cómo se desecha un par de gafas oscuras para ver más claro. No comprende que estas "prenociones" (es decir, las ideologías) son como el estrabismo y el daltonismo, parte 
integrante de la mirada, elemento constitutivo del punto de vista" $(1978,186)$. No tenemos duda que el daltonismo es un elemento constitutivo del punto de vista (Weltanschaung) para los centroamericanos.

El daltonismo presenta las características básicas con las que Lucien Goldmann define el punto de vista y/o cosmovisión; a saber, una estructura significativa global cuyo carácter es a la vez práctico, teórico y afectivo $(1985,7)$ que además contiene unos elementos normativos, los cuales definen "en una amplia medida, el campo de visibilidad de una teoría social, lo que esta "ve" y lo que no ve, sus "opiniones" y sus "errores", su luz y su ceguera, su miopía y su hipermetropía" (Löwy, 1978, 191).

Es sabido que los daltónicos frecuentemente confunden el verde y el rojo; sin embargo, pueden ver más matices del violeta que las personas de visión normal. Daniel Viglietti, en los versos de su canción Daltónica, nos señala: "Pobrecitos los poetas, ven visiones son daltones, donde hay huesos ven marrones, territorios prometidos como un sol".

Para Viglietti lo característico del daltonismo es la visión de futuro, la posibilidad de entrever "territorios prometidos como un sol", de saber que:

\section{"El Salvador será un lindo y sin (exagerar) serio país cuando la clase obrera y el campesinado lo fertilicen lo peinen lo talqueen \\ le curen la goma histórica lo adecenten lo reconstituyan y lo echen a andar." (Dalton, 2004, 478)}

Tenemos aquí un material que nos permitiría ver una suerte de elemento profético del daltonismo, para Dalton, anticipar la tierra prometida significa asumir éticamente los riesgos y las obligaciones de alcanzarla; saber que no siempre se va a llegar a ella. ${ }^{1}$

Este imaginario utópico y profético puede complementarse con un revelador fragmento de Un libro rojo para Lenin; allí se reproduce un pedazo de Tiempo y política de Regis Debray donde señala que: "Garantizar al máximo, mediante el análisis de lo dado, la justeza de la anticipación, es cosa del político como hombre de ciencia. Pero asumir el riesgo de la anticipación y probar su justeza mediante la acción, es cosa del sabio como hombre político" $(1985,77)$. 
Rigor teórico, riesgos insalvables más que por la acción decidida y voluntariosa, la acción como probatorio de la justeza de criterios: estamos en presencia de la famosa Tesis II que citamos más atrás; de aquí podemos inferir que el daltonismo sería el punto de vista, la concreción teórica de un proyecto de teoría social centroamericana. Esta teoría radical centroamericana tiene como uno de sus objetivos diseñar una estrategia de descolonización del marxismo centroamericano.

El daltonismo sería para los centroamericanos (a pesar del quaternio terminorum) una parte constitutiva del punto de vista rebelde.

Conclusión lógica: No se puede ser revolucionario en Centroamérica sin ser un poco daltónico. ${ }^{2}$

\section{Marxismo descolonizado: cultura revolucionaria y giro decolonial}

Roberto Fernández Retamar y el General Manuel Alemán Manzanares $^{3}$ (este último director de la policía de El Salvador durante de la dictadura de José María Lemus), ${ }_{1}^{4}$ coinciden en la significación histórico-continental del daltonismo.

El autor de Calibán sostiene que Dalton fue: "una de las grandes figuras de la revolución continental y aun mundial, y sus pariguales son Ernesto Guevara y Carlos Fonseca" (Fernández citado por Melgar, 1996). El General Alemán Manzanares, en el parte confidencial dirigido a Lemus, ha caracterizado a Dalton como "un elemento de lo más peligrosísimo para la tranquilidad nacional; está reseñado como un comunista de primera línea; constantemente vive agitando a la masa obrera, campesina y estudiantil, infiltrado sus ideas comunistas, poniendo en práctica consignas del comunismo internacional que ha recibido en cónclaves comunistas que se han celebrado en países detrás de la Cortina de Hierro" (Dalton, 2004, 96). Dalton consideró este parte, que se encuentra en la parte final de El Turno del ofendido como "el elogio de mi vida" (95).

En defensa del General Alemán Manzanares, hemos de decir que su capacidad para intuir la significación histórica de la obra de Dalton es por mucho superior a la de Fernández Retamar; el olvidado militar (si no fuera por la obra de Dalton) ya en 1960 sabía de la significación histórica del daltonismo. ${ }^{5}$

Uno de los proyectos más ambiciosos y más actuales del pensamiento latinoamericano es el Proyecto modernidad-colonialidad. 
Este proyecto epistémico y ético quiere mostrar que la modernidad y la colonialidad son "dos caras de la misma moneda".

Aníbal Quijano, Enrique Dussel, Walter Mignolo, Ramón Grosfoguel y Nelson Maldonado Torres son algunos de los nombres que se asocian con este proyecto de descolonización social y epistémica desde las periferias excluidas de la modernidad. ${ }^{6}$

El Proyecto Modernidad-Colonialidad señala que algunas de sus fuentes y anticipaciones son el Calibán de Fernández Retamar, Los condenados de la Tierra de Fanon, El discurso sobre el colonialismo de Césaire, así como la obra de Amílcar Cabral, José Carlos Mariátegui y René Zavaleta Mercado ${ }^{7}$. Algo que Ilama poderosamente la atención de esta genealogía ético-epistémica es el olvido (¿u ocultamiento?) de tres pensadores caribeños y centroamericanos cuya densidad y proyección intelectual los emparentaría directamente con Fanon, Césaire y Fernández Retamar: estamos pensando en Roque Dalton, Carlos Fonseca Amador y Ernesto Guevara.

La tríada Dalton-Guevara-Fonseca Amador ha sido más bien fuente de inspiración y análisis del grupo de intelectuales vinculado al proyecto Cátedra Che GuevaraColectivo Amauta y a La Rosa Blindada: Néstor Kohan, Fernando Martínez Heredia, Atilio Borón,
Jorge Beinstein son nombres que se asocian a este proyecto.

Este grupo intelectual, muchísimo más vinculado que los primeros a la militancia social y política, ha intentado encontrar en el mundo cultural y político latinoamericano de la década de los sesenta (ámbito del pensar indiscutido del guevarismo latinoamericano) su raíz y su fuente nutricia. La estela/ camino de la cultura revolucionaria latinoamericana de esta década es vista para "los blindados" como un firme punto de partida para relanzar teóricamente un proyecto de transformación social actual. ${ }^{8}$

Es motivo necesario de análisis el hecho de que, existiendo vasos comunicantes teóricos y personales entre ambos focos intelectuales (Fernández Retamar, Quijano, el dependentismo, la revolución cubana, las guerras de liberación nacional), las dos tradiciones o proyectos se ignoren mutuamente. Pese a ser un asunto importante, este hecho excede las pretensiones del ensayo en cuestión. ${ }^{9}$

El grupo modernidad-colonialidad pone mucho énfasis en el problema de la geopolítica del conocimiento.Al respecto, señala Ramón Grosfoguel que: "el punto central de las perspectivas epistémicas otras es la relación estrecha entre el lugar de la enunciación, esto es la geopolítica y corpo-política del sujeto que habla en las coordenadas del poder 


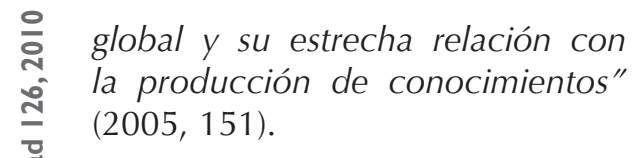

Encontramos pues varias categorías claves: geo y biopolítica del conocimiento, pensamiento fronteri$z^{10}$ y la herida colonial; esta última es muy importante porque funciona como garante de distinción epistémica y ética entre las modas e imposiciones académicas y el pensamiento radical y fundamental. ${ }^{11}$ La herida colonial es también un lugar epistémico y biopolítico desde el cual se escribe la diáspora africana en Césaire, la piel en Fanon, la frontera en Anzaldúa (Mignolo, 2005, 197-219).

Salvo que exista un desconocimiento de la obra daltónica (cosa poco probable) no habría razón para excluirle de las fuentes de las que habría de abrevar el giro decolonial. Una de las hipótesis que encontramos para este olvido es que puede haber un cierto exotismo en la selección de las genealogías decoloniales.

¿Por qué aparecería en las genealogías decoloniales Rigoberta Menchú y no Roque Dalton? Probablemente porque la obra de Dalton podría ser valorada como un pensamiento que llevaría más bien hacia la conciencia criolla blanca (Mignolo, 2000, 91-98) de estirpe morazánica y por ende ladina. ${ }^{12}$

Aquí es necesario comprender y asumir éticamente que la dimensión afrodescendiente y originaria tiene un fuerte componte de inscripción en la corporalidad; sin embargo hay autores que a pesar de su blanquitud física (que es un dato biológico), su proyecto ético-político les permite ingresar a las categorías de los interesados/comprometidos en la descolonización social y epistémica; es decir, pueden volverse negros e indios.

El filósofo cubano Félix Valdés, junto con el filósofo venezolano Lino Morán han propuesto una posible lectura decolonial, en este caso de la obra de José Martí. Señalan estos autores: "José Martí es uno de los pensadores esenciales de la América que se enfrenta, desde el pensamiento y la acción revolucionaria, al colonialismo español, a los patrones y modelos de la colonialidad —entendido este fenómeno como el conjunto de ideales, normas, valores, más allá del estatus legal de dependencia a una u otra metrópolis-, a pesar de la complejidad que esta crítica implica por darse en un mundo que ha naturalizado la esclavitud negra, la ineptitud del indígena, la incapacidad del otro frente a la cultura del colonizador" (...) "José Martí, nace en una isla del Caribe que conocía de la esclavitud y de un mundo que tenía al negro por esclavo y donde el color de la piel, precisamente el color negro, era un signo negativo. Su recuerdo de niño al ver a un esclavo muerto "colgado a un seibo del monte" que le hiciera temblar, le hizo también jurar 'al pie del 
muerto', 'lavar con su sangre el crimen'. En otra ocasión dejó dicho de modo tajante: " $i Y$ los negros? ¿Quién que ha visto azotar a un negro no se considera para siempre su deudor? Yo lo vi, lo vi cuando era niño, y todavía no se me ha apagado en las mejillas la vergüenza... Yo lo vi, y me juré desde entonces a su defensa". $(2008,23)$.

Esta posibilidad de "transsujetización" podría ser pensable para instituciones como un todo (especialmente cuando estén en marcadas en un proceso de transformación social radical): ese es el sentido del famoso discurso de Ernesto Guevara al recibir el título de Profesor Honoris Causa de la Universidad Central de Las Villas $(2007,11)$.

Podemos rastrear el pensamiento fronterizo y la herida colonial en dos obras claves de Dalton: Un Libro rojo para Lenin y Las historias prohibidas del Pulgarcito, así como en varios de sus poemas más conocidos.

La primera reflexión clara en ello es un pasaje de Un libro rojo para Lenin, donde Dalton responde una objeción efectuada por el tono zumbón y constantemente irrespetuoso de su poema-collage; "Recuerde usted que pienso y hablo en el centro del vientre de la ballena neocolonial. Yo, el poeta, soy en este caso y en general, el colonizado y la voz del colonizado. El co- lonizado que durante muchos años asumió como colonizado inclusive la teoría y la práctica revolucionaria. (...) Así, en una maroma histórica doblemente aplastante, la cultura del colonizador y la cultura revolucionaria de la humanidad más avanzada (la clase obrera liberada) fue para nosotros carne y bocado de enajenación, aunque a distintos niveles" $(1985,120)$.

Más adelante afirma que: "en la tarea de búsqueda de nuestra identidad y del rescate del arsenal de la experiencia histórica de los pueblos, los poetas colonizados-pero-enproceso-de-descolonización aportamos una actitud social concreta y un tipo concreto de lenguaje" (120).

Se entiende entonces que colonizados-pero-en-proceso-de-descolonización es justamente la idea de la episteme fronteriza y la herida colonial. Desde ese lugar epistémico y ético y con la consecuente política de la memoria que se produce en ese proceso/esfuerzo de descolonización, es que se arma Dalton para enfrentarse a su proyecto de "ayudar, por todos los medios a su alcance en la ubicación inequívoca del marxismo-leninismo en y para América Latina" (29).

$\mathrm{Su}$ proyecto de construir un marxismo desde el "vientre de la ballena neocolonial", a la vez epistémico, ético-político y estéti$\mathrm{co}$, fue siempre concebido como una batalla de ideas, que es solo 
un momento de la batalla efectiva: "AAy de los que creen que porque la verdad es concreta ella es sólo como una piedra, como un bloque de hormigón o un ladrillo! Una bicicleta, un jet, una astronave, son cosas concretas como la verdad. Lo mismo que un rompecabezas. $Y$ un combate cuerpo a cuerpo" (27). En esto Dalton retoma la más clásica tradición marxista: "el arma de la crítica no puede sustituir a la crítica de las armas" (Marx, 1984,10).

Si bien el imaginario básico dominante en Centroamérica forjó su relación con Europa y Estados Unidos más como una conciencia geográfico-política (Taracena, 1995,45-63) que como una conciencia racial y social (que sería el caso del Caribe anglo y francorparlante), no parece posible que se pueda clasificar al pensamiento centroamericano como una variante sin más de la conciencia criolla, blanca, sajona o ibérica (Mignolo, 2000, 79-119).

En el ámbito del pensar de los autores radicales centroamericanos hay varias heridas coloniales profundas desde las cuales se reflexiona y se escribe. En Dalton salta a la vista la presencia permanente de tres heridas coloniales: el desmembramiento nacional centroamericano (es decir la "ausencia de patria"), la matanza de 1932 y lo que Ernesto Guevara Ilama la categoría hambre del pueblo. ${ }^{13}$
Veamos el fragmento 29 de Un libro rojo para Lenin, intitulado Un campesino de mi país habla de la teoría y la práctica: "A la hora en que me traiga chaqueteando la guardia jaquí tienen sus fronteras y sus ojitos de cangrejo! Si las fronteras donde único que están es en los mapas y las aduanas. En realidad sólo hay tierra pelona. Y pobres, por todos lados. ¿O es que la tierra de Honduras y El Salvador sólo va a servir para que los ejércitos de los gobiernos de los ricos se maten entre sí y maten gente inocente en guerritas de mierda que sólo sirven para joder más al pueblo?" (1985, 97).

La guerra de la que se habla es la "Guerra del Fútbol". Esta guerra de los ricos, pensada desde la herida colonial, genera una política de la memoria que remite directamente a 1932 (y más atrás al levantamiento de Anastasio Aquino en 1833).

Miguel Mármol señala en su testimonio sobre la matanza de 1932 (recogido por Dalton en 1966): "nuestra tradición centroamericanista es un hecho y aunque la burguesía y los gringos siempre han atizado la división, la verdad es que somos una sola nación, partida en cinco pedazos" (Dalton, 2000, 422).

Según Dalton las palabras del campesino que citamos arriba resumen "con sus palabras que son 
las palabras del pueblo de mi país las concepciones más generales de Lenin (...) ese campesino desarroIla simplemente, en mi lugar, ese aspecto básico para nosotros del pensamiento de Lenin". $(1985,94)$.

Es decir estamos en presencia de una lectura bio y geopolítica del leninismo, el leninismo leído y entendido, ya no solo desde la herida colonial del desmembramiento nacional, sino que también desde el hambre del pueblo.

"Cuando los pobres hondureños y los pobres guatemaltecos sepan que los pobres salvadoreños son sus hermanos para echarles verga a los ricos salvadoreños, a los ricos hondureños y a los ricos guatemaltecos, otro gallo va a cantar" $(1985,97)$

Para Dalton la herida colonial de los centroamericanos es justamente el despojo de la patria; si algún sentido puede tener en Centroamérica la frase "los proletarios no tienen patria" es justamente que hemos sido despojados de ella, que el patrón de poder moderno/colonial nos ha condenado a no tener patria.

"Seremos socialistas porque somos patriotas; No termina el mundo en nuestro país pero estamos en el mundo: como salvadoreños, bajo la misma bandera de Lenin y Farabundo Martí, nos alzaremos de nuestra pequeñez con las cadenas rotas" $(1985,134)$.

Este alzamiento desde nuestra pequeñez solo tiene sentido si las clases subalternas logran transcrecer las fronteras, si se sana la herida colonial que nos condena a vivir en seis repúblicas bananeras.

Los poemas El alma nacional (I) y El gran despecho (II) son representaciones bastante contundentes de esta reflexión sobre el despojo de la patria, de su inexistencia efectiva y por lo tanto del desgarramiento social y epistémico que nos constituye.

(I) "Patria dispersa: caes

como una pastillita de veneno en mis horas.

¿Quién eres tú, poblada de amos, como la perra que se rasca junto a los mismos árboles que mea? ¿Quién soportó tus símbolos, tus gestos de doncella con olor a caoba, sabiéndote arrasada por la baba del crápula?

¿A quién no tiernes harto con tu diminutez? ¿A quién aún convences de tributo y vigilia?

¿Cómo te llamas, si, despedazada, eres todo el azar agónico en los charcos? 
¿Quién eres,

sino este mico armado y numerado,

pastor de llaves y odio, que me alumbra la cara?

Ya me bastas, mi bella

madre durmiente que haces heder la noche de las cárceles:

ahora me corroen los deberes del acecho

que hacen del hijo bueno un desertor, del pavito coqueto un pobre desvelado, del pan de Dios un asaltante hambriento.

Penitenciaría Central, Octubre 1960"

(Dalton, 2004, 260).

(II) "País mío no existes

sólo eres una mala silueta mía

una palabra que le creí al enemigo

Antes creía que solamente eras muy chico

que no alcanzabas a tener de una vez

Norte y Sur

pero ahora sé que no existes

y que además parece que nadie te necesita

no se oye hablar a ninguna madre de ti

Ello me alegra

porque prueba que me inventé un país

aunque me deba entonces a los manicomios

Soy pues un diosecillo a tu costa

(Quiero decir: por expatriado yo

tú eres ex patria)"

(Dalton, 2004, 260).

Debemos ahora conectar el problema de quiénes son condenados de la ex patria y condenados de la Tierra. La conexión se presenta en la forma específica en la que se despliega la dialéctica entre 
colonización y descolonización, en la forma específica en que se construye la praxis que nos permite ser colonizados-pero-en-proceso-dedescolonización.

Es importante aquí tomarnos un momento para explicar la categoría de "don decolonial" y la relación condenador-condenado. Citaré en extenso a Nelson Maldonado Torres: "El 'don decolonial' se refiere en este caso a la razón del esclavo o del condenado. Césaire encuentra en la misma una contribución fundamental para que Europa responda a su crisis. La existencia del esclavo mismo puede interpretarse como una reclamación o exigencia, o bien como una apelación a la decisión sobre la persistencia de la esclavitud o su ruptura. La ceguera o falta de apertura ante la oferta gratuita o «don» del esclavo no es circunstancial, sino que le es inherente a la situación colonial y de esclavitud racial misma. La noción de condena, a la que se refieren tanto Césaire como Fanon al hablar del colonizado como un condenado, remite precisamente a una situación en la cual los sujetos han sido despojados de sus «dones» o de los recursos que tienen para ofrecer a otros. Me baso aquí en la etimología de damné o condenado, que hace referencia a donner en el francés, y que literalmente significa 'aquel que no puede ofrecer nada porque sus recursos le han sido arrebatados'. Tanto Césaire como Fanon entienden la colonización como un despojo de los recursos con que sujetos o pueblos cuentan para ofrecer a otros. La ofrenda, en este caso, se entiende como una muestra de la humanidad de tales sujetos, y es distinta de la concepción hegeliana de la lucha por el reconocimiento." $(2005,189)$.

La dialéctica del amo y el esclavo de la Fenomenología del espíri$\mathrm{tu}^{14}$ es pues superada y descolonizada para encontrar la dialéctica entre el condenado y el condenador, la dialéctica de "aquel que no puede ofrecer nada porque sus recursos le han sido arrebatados" y el arrebatador de recursos.

La sugerente interpretación de Maldonado Torres genera elementos para construir una "dialéctica daltónica" que mezclaría dos de las heridas coloniales: la de hambre del pueblo y la de matanza de 1932. Sería una dialéctica entre los medio vivos y los medio muertos que se encuentra en el poema Todos:

"Todos nacimos medio muertos en 1932 sobrevivimos pero medio vivos cada uno con una cuenta de treinta mil muertos enteros que se puso a engordar sus intereses sus réditos

y que hoy alcanza para untar de muerte a los que siguen 
naciendo

medio muertos

medio vivos

Todos nacimos medio muertos en 1932

Ser salvadoreño es ser medio muerto eso que se mueve

es la mitad de la vida que nos dejaron

Y como todos somos medio muertos

los asesinos presumen no solamente de estar totalmente vivos

sino también de ser inmortales

Pero ellos también están medio muertos y sólo vivos a medias

Unámonos medio muertos que somos la patria para hijos suyos podernos llamar

en nombre de los asesinados unámonos contra los asesinos de todos contra los asesinos de los muertos y los mediomuertos

Todos juntos tenemos más muerte que aquellos pero todos juntos tenemos más vida que ellos

La todopoderosa unión de nuestras medias vidas de las medias vidas de todos los que nacimos medio muertos en 1932."

(Dalton, 2007, 124-125).

\section{El estilo daltónico: Ironía y collage}

Analizando el estilo literario de Roque Dalton, hay dos aspectos que destacan con facilidad en su obra: la ironía y el concepto/estilo del poema-collage. 
La ironía como expresión de la dialéctica entre colonialidad y descolonización es clave para comprender la actualidad del daltonismo, tal como señala Kohan en su reflexión sobre el estilo daltónico: "Al entablar una batalla ideológica de largo aliento contra todo un abanico de reformismos Roque logra conjugar un contenido revolucionario con una forma de expresión que violenta las cristalizaciones habituales del discurso de izquierda. Su estilo disruptivo, heterodoxo, iconoclasta, no es ajeno al contenido que pretende transmitir." (2009).

Ludovico Silva, al analizar el estilo literario de Marx, manifiesta que los módulos estilísticos, sobretodo la ironía, "no son de modo alguno casualidades, ocurrencias ingeniosas o simples ornamentos con que un científico ilustra su pro- sa con tal de hacerla más accesible, sino que por el contrario, constituyen un todo armónico con el sistema conceptual" (...) "[la ironía] nos describe primero las apariencias felices de las relaciones sociales para luego denunciar su estructura real y miserable" $(1980,117)$.

Una de las relaciones sociales en la cual recurrentemente se centra la mirada daltónica y donde podemos ver expresivamente la importancia de la ironía en el conjunto de su pensamiento/crítica es en la colonialidad del pensar, más precisamente en la colonización de los intelectuales del tercer mundo. La ironía daltónica quiere mostrar el papel "real y miserable" que juegan los intelectuales colonizados dentro del capitalismo dependiente latinoamericano. Señala su poema "Cartita":

"Queridos filósofos, queridos sociólogos progresistas, queridos sicólogos sociales: no jodan tanto con la enajenación aquí donde lo más jodido es la nación ajena."

(Dalton, 2004, 475)

En múltiples poemas y ensayos podemos encontrar esta arquitectura estilística que busca develar y de esta manera contribuir a la destrucción de las estructuras básicas del dominio oligárquico-imperialista: la iglesia católica, el catolicismo social, el arielismo latinoamericano son sometidos a este proceso de develación irónica.

Pero esta ironía sirve también para criticar y denunciar al socialismo colonizado latinoamericano ${ }^{15}$. Los partidos comunistas latinoamericanos, sus intelectuales orgánicos 
y periféricos y sobretodo su praxis teórico-política son también focos de la ironía daltónica. Esto se ve con claridad en su poema Lógica Revi:

\author{
"Una crítica a la Unión Soviética \\ sólo la puede hacer un antisoviético. \\ Una crítica a China \\ sólo la puede hacer un antichino. \\ Una crítica al Partido Comunista Salvadoreño \\ sólo la puede hacer un agente de la CIA. \\ Una autocrítica equivale al suicidio."
}

(Dalton, 2007, 109)

En el Fragmento 14 de Un libro rojo para Lenin, vuelve con más sustento teórico-histórico, sobre el mismo problema: "Cuando yo ingresé en el partido (a través de una reunión de célula que ya he dejado escrito en un poema) el primer material de estudio que puso en mis manos la organización fue El izquierdismo, enfermedad infantil del comunismo. (...) Entonces no sabia yo que hay personas que definen para siempre el Partido Comunista como 'un partido que no ha tomado aún el poder' e incluso como 'un partido que acumula fuerzas', lo cual eleva toda táctica y toda maniobra a un campo de metafísica existencial que ni el reverendo Berkeley fue capaz imaginar" $(1985,63)$.

$\mathrm{El}$ comunismo ortodoxo y filosoviético latinoamericano, es claramente el rival preferido de
Dalton en el terreno de la batalla de ideas dentro del campo de la izquierda, pero tampoco es la única interpretación sujeta a crítica; son menos conocidas, pero igual de radicales las críticas, por ejemplo, a la Izquierda Nacional Argentina (Benedetti, 1969), crítica que sería extensiva a las posiciones políticas de Nahuel Moreno y Joe Hansen (Kohan, 2009). Asimismo la crítica y la ironización de la experiencia chilena no es difícil de detectar: "Cuando usted tenga el ejemplo de la primera revolución socialista hecha por la vía pacífica, le ruego que me llame por teléfono. Si no me encuentra en casa, me deja un recado urgente con mi hijo menor, que para entonces ya sabrá mucho de problemas políticos" (Dalton citado por Kohan, 2009).

El poema Poeta libre apunta en el mismo sentido: 
Cuba sí.

Yanquis también.

Nicanor ParRa

¿Chile?

Depende...

(Dalton, 2004, 415)

La ironía daltónica juega un papel muy importante en el plano de la lucha político-ideológica, de la diferenciación política, pero también es parte integrante y funcional del conjunto de la visión daltónica de mundo. Todas las instituciones que ha construido el moderno patrón de dominio son sometidas a la crítica de las armas.

Es importante señalar que en los hechos la posición política de Dalton es expresión de una corriente muy precisa y muy pequeña de la izquierda latinoamericana.

Pese a la popularidad icónica de los guevaristas latinoamericanos: Dalton, Santucho, Fonseca Amador, el mismo Guevara. En realidad sus tesis básicas: la actualidad de la revolución socialista en el Tercer Mundo, las organizaciones políticomilitares como catalizador del descontento popular, el campesinado como sujeto social de la revolución, el papel de la subjetividad y la voluntad en la conquista del poder y en la transición socialista (la teoría del hombre nuevo) no son tesis con las que operen sectores significativos de la izquierda latinoamericana, inclusive la izquierda armada (aunque todos reivindiquen las figuras de los guevaristas). Esta situación especial donde todos y ninguno somos daltónicos, es efectivamente paradójica e irónica. ${ }^{16}$

Este es el momento donde más vale advertir que estamos "combatiendo a la sombra", así que solo queremos delinear algunos posibles caminos de análisis. Nos parece que para poder "sacar algo en limpio" del estilo daltónico es necesario realizar una análisis más meditado de la situación especial que vive la intelectualidad radicalizada latinoamericana y centroamericana en los años sesenta y sus posteriores trasformaciones sociológicas e ideológicas (labor que sobrepasa por mucho los objetivos de este ensayo).

En todo caso creemos que no es improductivo intentar una comparación entre lo que Lucien Goldmann Ilama la visión trágica del mundo $(1985,11-119)$ y el daltonismo.

Existe por lo menos un aspecto donde se encuentra una línea ana- 
lógica e investigativa que estimamos plausible: en el problema de la forma de la escritura.

Hay una pregunta poco realizada en los analistas de Dalton: ¿Por qué los documentos teóricospolíticos más importantes de Dalton (El libro rojo para Lenin y Las historias prohibidas del pulgarcito) son un poema-collage? Es como, señala correctamente Kohan (2009), imposible ver en Dalton un antecesor del

videoclip posmoderno ${ }^{17}$; la presencia de la historia, la ideología y el sujeto y su hostilidad hacia el oficio académico definitivamente vuelven incompatibles el posmodernismo y el daltonismo. Aun así Kohan no explica por qué en su obra de madurez, Dalton escoge el poemacollage como forma expresiva y no por ejemplo el ensayo sociológico, el testimonio autobiográfico o el periodismo, todos ellos géneros que Dalton cultivó y utilizó con maestría.

Goldmann sostiene que el fragmento es probablemente una de las formas privilegiadas de la escritura trágica; la visión trágica del mundo tiene entre sus características responder si y no a todos los problemas fundamentales del ser humano y su relación consigo mismo, con otros seres humanos y con el cosmos/naturaleza.

Estimamos que se puede buscar este elemento trágico en la obra de
Dalton y más que en él, en la época y en el grupo social que Dalton sintetizó y animó en su práctica política y estética.

Un elemento que después de algunas lecturas salta a la vista es que a todos los problemas fundamentales de la historia, la política y la estética Dalton responde sí y no: ¿tenemos patria? Sí y no. ¿Podemos vencer a un enemigo implacable? Sí y no. ¿Podremos descolonizarnos? Sí y no. ¿Este poema concluirá? Sí y no. ¿Me ama? Sí y no.

Parece haber algo profundo y complejo que Dalton intuye e inclusive comprende, pero de lo que solo nos deja rasgos y atisbos, su batalla descolonizadora parece atacar a las mismas estructuras del lenguaje y sus posibilidades comunicativas. Probablemente por eso, más que sus textos, nos habla su testimonio global, profundamente coherente, pero por eso mismo paradójico.

Una investigación más profunda debería revisar a profundidad esta relación entre ironía, tragedia, política y la forma del poema-collage. Por el momento solo presentamos algunas intuiciones.

Para concluir quiero presentar un enigmático poema, que parece sintetizar las relaciones entre despojo patrio, heridas coloniales, visiones trágicas y cultura revolucionaria: 
Dos patrias tengo yo:

Cuba

y la mía

(Dalton, 2004,412).

Bibliografía:

Bell, J.; López, D. y Caram, T. (2007) Documentos de la Revolución Cubana 1960. La Habana: Editorial de Ciencias Sociales.

Camacho, L. (2002) Introducción a la Lógica. ( $1^{\circ}$ Edición) Cartago: Libro Universitario Regional.

Césaire, A. -et. al.- (2005) Discurso sobre el colonialismo. Madrid: Akal Ediciones.

Dalton, R. (1982) Miguel Mármol. Los sucesos de 1932 en El Salvador. Centroamérica: EDUCA.

(1984) El Salvador (Monografía). La Habana: Enciclopedia Popular CASA.

(1985) Un Libro rojo para Lenin. Managua: Editorial Nueva Nicaragua.

(2004) La ternura no basta. Antología poética. La Habana: Casa de las Américas. (2007) Antología Poética de Roque Dalton. sfe.

(2008) Las historias prohibidas del pulgarcito San Salvador. San Salvador: UCA Editores.

Gallardo, H. (1993) Fenomenología del Mestizo. San José: DEI.

Goldmann, L. (1985) El Hombre y lo Absoluto. (Trad. Juan Ramón Capella) Barcelona: Ediciones Península.

Grosfoguel, R. (2005) Actualidad del pensamiento de Césaire: redefinición del sistema-mundo y producción de utopía desde la diferencia colonial en Césaire, A. -et. al.- (2005) Discurso sobre el colonialismo. Madrid: Akal Ediciones.

Guevara, E. (1968) Obra Revolucionaria. México: Ediciones Era.

Kohan, N. (2003) Marx en su (Tercer) Mundo. Hacia un socialis- 


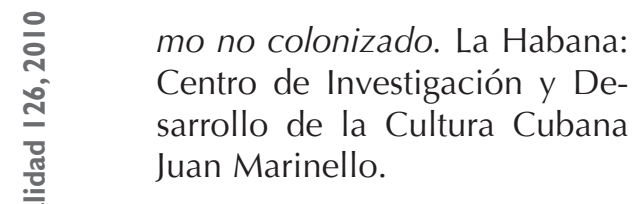

(2004) Che Guevara: El sujeto y el poder. Buenos Aires: Cátedra Che Guevara.

(2007) La concepción de la revolución en el Che Guevara y en el guevarismo. (Aproximaciones al debate sobre el futuro de América Latina y el socialismo del siglo XXI desde el marxismo revolucionario latinoamericano). Buenos Aires: Material de formación política de la «Cátedra Che Guevara Colectivo AMAUTA».

(2007) Desafíos actuales de la teoría crítica frente al posmodernismo. Buenos Aires: Material de formación política de la «Cátedra Che Guevara Colectivo AMAUTA».

Löwy, M. (1978a) Dialéctica y Revolución. (Trad. Aurelio Garzón del Camino, 2a ed.) México: Siglo XXI Editores.

Maldonado Torres, N. (2005) Aimé Césaire y la crisis del hombre europeo en Césaire, A. -et. al.- (2005) Discurso sobre el colonialismo. Madrid: Akal Ediciones.
Martínez Heredia, F. (2001) El corrimiento hacia el rojo. La Habana: Ediciones Letras Cubanas.

(2006) Socialismo, Liberación y Democracia. La Habana: Ocean Sur.

Marx, K. y Engels, F. (1984) La sagrada familia. (Trad. Carlos Liacho) México: Grijalbo.

(1978) La ideología alemana. (Trad. Wenceslao Roces, $3^{a}$ ed.) México: Ediciones de Cultura Popular.

Mignolo, W. (2000) La colonialidad a lo largo y a lo ancho: el hemisferio occidental en el horizonte colonial de la modernidad en Lander, E. (Comp.). (2000) La colonialidad del saber: eurocentrismo y ciencias sociales. Buenos Aires: CLACSO.

(2005) El giro gnoseológico decolonial: La contribución de Aimé Césaire a la geopolítica y la corpo-política del conocimiento en Césaire, $\mathrm{A}$. -et. al.- (2005) Discurso sobre el colonialismo. Madrid: Akal Ediciones.

Taracena, A. y Piel, J. (1995) Identidades nacionales y Estado Moderno en Centroamérica. San José: Editorial de la Universidad de Costa Rica. 
Silva, L. (1980) El estilo literario de Marx. México D. F: Siglo XXI Editores.

VV. AA. (2006) Marxismo y revolución. Escena del debate cuba-

Artículos de revistas

- Benedetti, M. (1969) "Una hora con Roque Dalton". Revista Marcha: Febrero-Marzo 1969.

- Grosfoguel, R. (2006) "La descolonización de la economía política y los estudios postcoloniales: transmodernidad, pensamiento fronterizo y colonialidad global". Tabula Rasa, $N^{\circ}$ 4: 17-48.

Publicaciones en Internet

- Bou, L. "África y la Historia". En http://www.nodo50.org/observatorio/africa.htm. Revisado: 11 de octubre de 2009.

- "Daltonismo" en http:// es.wikipedia.org/wiki/Daltonismo. Revisado: 25 de septiembre de 2009. no en los sesenta. La Habana: Editorial de Ciencias Sociales/ Centro de Investigación y Desarrollo de la Cultura Cubana Juan Marinello.

- Melgar Brizuela, L. (1995) "A veinte años de su muerte. ¿Releer a Dalton? ¿En cuál circo?" Revista Tendencias, № 40.

- Mignolo, W. (2005) "Cambiando las éticas y las políticas del conocimiento: lógica de la colonialidad y postcolonialidad imperial". Tabula Rasa, No 3: 47-72.

- Valdés, F. y Morán, L. (2008) "Martí y el conflicto de razas". Revista Cubana de Ciencias Sociales (en prensa).

- Kohan, N. (2009) "Un diálogo con Roque Dalton y Lenin, desde el siglo XXI". En http://www.rebelion.org/noticia. php?id=85666. Revisado: 11 de octubre de 2009.

- Viglietti, D. "Daltónica". En http://www.cancioneros.com/ nc/6003/0/daltonica-danielviglietti. Revisado: 25 de septiembre de 2009. 


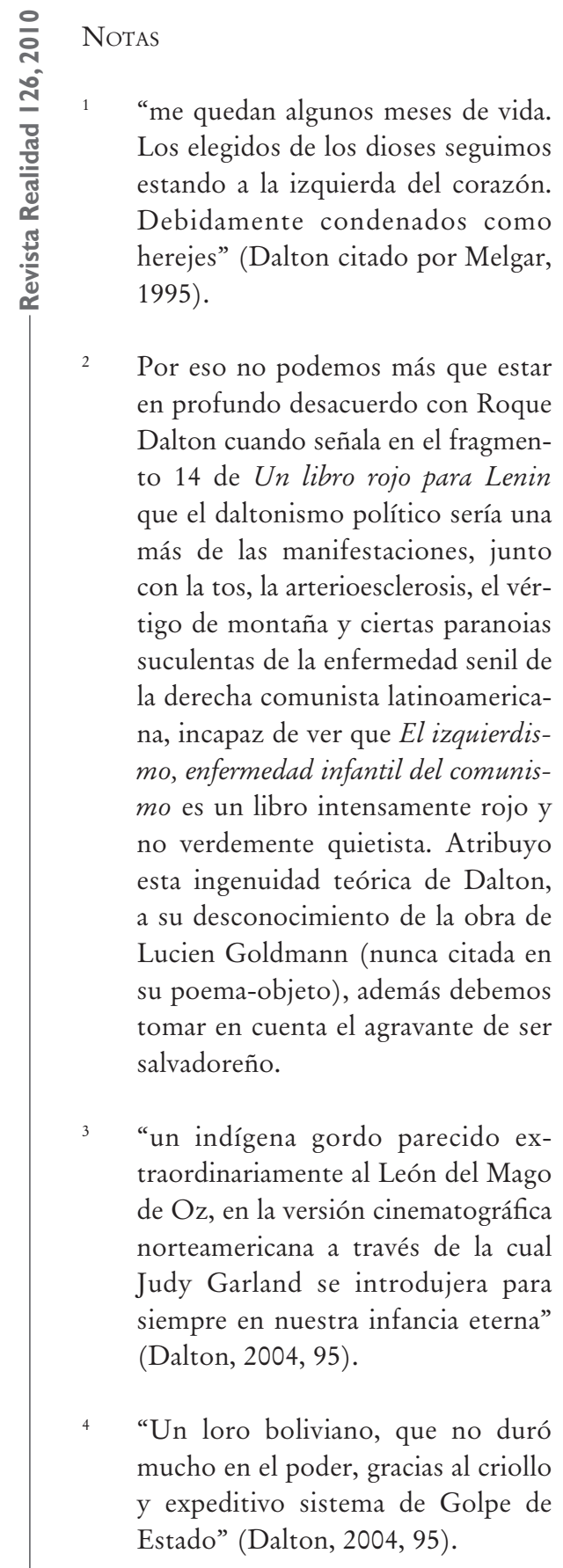

5 El General Alemán fue probablemente uno de los principales impulsadores del proceso de radicalización intelectual de Dalton, como el mismo señala: "Mis verdaderas obras eran tan insignificantes que no aparecían por ninguna parte en el parte: el general Manzanares actuaba en rectificación del verdadero vacío de mi vida" (Dalton, 2004, 97).

6 "Descolonización se refiere aquí no sólo a la crítica a las relaciones neocoloniales que continuaron y renovaron de distintas formas la dependencia y las relaciones verticales de poder entre países del norte y países del sur, sino más bien a la búsqueda de la transformación del patrón de poder moderno/colonial que continua definiendo las identidades modernas y las relaciones intersubjetivas de poder y de conocimiento que se derivan de las mismas" (Maldonado, 2005, 174).

“(...) me encuentro reflexionando y escribiendo sobre la geopolítica del conocimiento y el cambio que, en América Latina, fue introducido por la teoría de la dependencia, así como por la filosofía y la teología de la liberación. También he pensado sobre la importancia y las consecuencias de cambios similares en el Caribe, desde la década de 1950 con las intervenciones radicales de Aime Cesaire ('Discurso sobre el colonialismo'), Frantz Fanon (Piel negra, máscaras blancas y Los condenados de la tierra) y Amílcar Cabral (Return to the Sources. Selected Spee- 
ches), así como sobre las cuestiones planteadas por la filosofía africana subsahariana (una cuestión similar fue hecha, en el mismo tiempo, en América Latina). Estoy convencido, como lo estaba el sociólogo e intelectual boliviano René Zavaleta Mercado (1986), de que el entendimiento de las sociedades semi-coloniales y dependientes (como Bolivia) demanda considerar la dependencia epistémica." (Mignolo, 2005, 50).

Néstor Kohan en su articulo La concepción de la revolución en el Che Guevara y en el guevarismo. (Aproximaciones al debate sobre el futuro de América Latina y el socialismo del siglo XXI desde el marxismo revolucionario latinoamericano) señala: "En este trabajo intentamos sintetizar y conjugar en una visión de conjunto sobre la concepción de la revolución en el Che Guevara y en el guevarismo hipótesis, sugerencias, análisis y conclusiones presentes en otros artículos, ensayos y libros donde, en forma dispersa, hemos intentado ir recuperando el aporte específicamente político de distintos guevaristas (Robi Santucho, Miguel Enríquez, Roque Dalton, etc.). De alguna manera este texto intenta hilar y enhebrar esos abordajes parciales dentro de un conjunto mayor, para tratar de mostrar que existe una concepción general integrada por todos ellos (de la cual nosotros, varias décadas después, aspiramos a formar parte, retomándola y recreándola, de acuerdo a nuestra época)" $(2007,1)$. Algunos artículos y libros que considero claves e ilustrativos para entender este proyecto, además de la cultura revolucionaria de los 60 (sobretodo en Cuba) son: Corrimiento al rojo (2001), Socialismo, liberación $y$ democracia (2006) de Fernando Martínez Heredia, así como la obra colectiva Marxismo y revolución (2006).

Es importante señalar en todo caso, que en específico Kohan ni desconoce, ni ignora el Proyecto modernidad-colonialidad, en su caso lo que hay es una abierta hostilidad: "En los Estados Unidos, ese proceso de pasteurización y asepsia forzada de la teoría crítica llegó al extremo con los estudios "poscoloniales", una parodia lastimosa y miserable del anticolonialismo militante de un Fanon, un Che Guevara o un Ho Chi Minh, por no mencionar a las Panteras Negras o a Malcolm X...” (2007).

10 El pensamiento fronterizo: "es la respuesta epistémica de lo subalterno al proyecto eurocéntrico de modernidad. En lugar de rechazar la modernidad para retirarse en un absolutismo fundamentalista, las epistemologías fronterizas subsumen/ redefinen la retórica emancipatoria de la modernidad desde las cosmologías y las epistemologías de lo subalterno, localizado en el lado oprimido y explotado de la diferencia colonial, hacia una lucha por la liberación descolonial por un mundo más allá de la modernidad eurocentrada." (Grosfoguel, 2006, 39). 


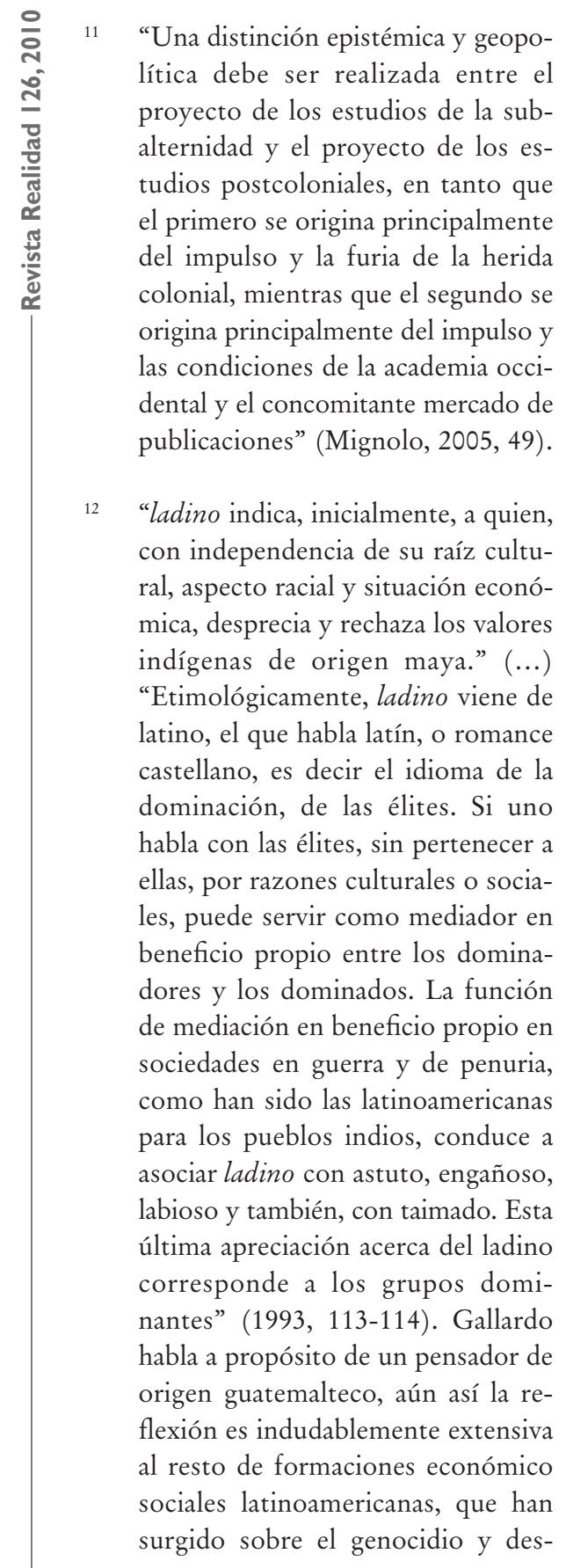

precio de las sociedades originarias, independientemente del nivel de desarrollo de fuerzas productivas y “democratización” (cualquier cosa que esto signifique en sociedades dependientes) que estas alcanzaron, es importante señalar que para Gallardo el "ser ladino" es sobre todo una actitud y bajo determinadas condiciones el ladino puede (pese a sus sensibilidad desgarrada) convocar y construir espacios de liberación social y nacional.

13 Se pueden encontrar estas reflexiones en el Mensaje a los pueblos del mundo a través de la Tricontinental y un comentario más extendido en Che Guevara. El sujeto y el poder de Néstor Kohan.

No está demás señalar que en los fundadores de la dialéctica trágica (Kant) y la dialéctica idealista (Hegel) la presencia del ocultamiento racista de la razón colonial es más que patente citamos en el caso de Kant sus Observaciones sobre lo bello $y$ lo sublime (a) y de Hegel un pasaje de Filosofía de la Historia (b): "Los negros de África carecen por naturaleza de una sensibilidad que se eleva por encima de lo insignificante. El señor Hume desafía a que se le presente un ejemplo de que un negro haya mostrado talento, $y$ afirma que entre los cientos de millares de negros transportados a tierras extrañas, y aunque muchos de ellos hayan obtenido la libertad, no se ha encontrado uno sólo que haya imaginado algo grande en el arte, en la 
ciencia o en cualquiera otra cualidad honorable, mientras entre los blancos se presenta frecuentemente el caso de los que por sus condiciones se levantan de un estado humilde y conquistan una reputación ventajosa. Tan esencial es la diferencia entre estas dos razas humanas; parece tan grande en las facultades espirituales como en el color." (Kant citado por Mignolo, 2005, 199) (b) "De algunos de estos trazos se deduce que es la incivilidad lo que caracteriza al hombre de color. La única relación que han tenido los negros con los europeos y todavía tienen es la de la esclavitud. Por lo general no ven los africanos en la misma algo absolutamente repudiable. Es así que tan luego los británicos, que tanto están haciendo en pro de la abolición de la esclavitud, son peor mirados por los negros. (...) Con esto abandonamos el tema de África, por cuanto no se trata en nuestro análisis de un continente histórico. No nos ofrece, en razón de su estatismo y de su falta de desarrollo, material de alcance constructivo. (...) Lo que entendemos como África es lo segregado y carente de historia, o sea lo que se halla envuelto todavía en formas sumamente primitivas, que hemos analizado como un peldaño previo antes de incursionar en la historia universal.” (Hegel citado por Bou: 1976)

"La versión deformada y teologizante del marxismo, que contenía gran parte de la literatura a nuestro alcance, resultó ineficaz para contri- buir a formar revolucionarios capaces de analizar y resolver nuestras situaciones concretas; al contrario, amenazó agudizar la pereza y 'manquedad' mental típica del individuo colonizado, en una etapa en que el atraso económico y las dificultades de todo orden exigen el desarrollo rápido del espíritu creador. En realidad esto ha sido, parcialmente, una forma de pervivencia del 'marxismo' subdesarrollado, que une la pretensión de ortodoxia a un abstractismo totalmente ajeno a Marx y a Lenin.” (Martínez Heredia citado por Kohan, 2003, 27).

Hay otro elemento evidente de paradoja e ironía en la vida y en la práctica política de Dalton: Su muerte. En ese sentido el artículo de Kohan dedicado a Dalton, posee un profundo defecto al no atender este hecho. Las conclusiones epistémicas y políticas de la propuesta daltónica no solo son insoportables para el progresismo bienpensante y para estalinismo criollo, el militarismo y el verticalismo de las organizaciones político-militares centroamericanas (inspiradas mayormente en la experiencia cubana) también es amenazado por su ironía. No debemos olvidar que en la extraña muerte de Dalton, todos los índices apuntan al entonces comandante del Ejército Revolucionario del Pueblo, Joaquín Villalobos. La estructura de mando debido de las organizaciones político-militares fue la que al final dieron al traste con la vida de Dalton, no fueron curas extremistas, 


burguesía o agentes internacionales
de la KGB quienes mataron a Dal-
ton, sino sus propios compañeros de
armas. Este hecho insólito inclusive
en la reducida esfera de los gue-
varistas latinoamericanos, quienes
normalmente murieron en embos-
cadas o combatiendo contra las FF.
AA. abona al asombro que produce
la vida y obra de Roque Dalton.
En este sentido la muerte herética
de Dalton debería contribuir a un
proceso de reflexión del grupo vin-
culado a La Rosa Blindada, reflexión
donde juega una papel importante la
crítica leninista (de último periodo),
trotskista y consejista al problema
de la democracia interna dentro de
las organizaciones revolucionarias
y del valor intangible que tiene para
los procesos revolucionarios la poli-
fonía socialista.

“(..) el collage de Roque no es posmoderno, pues su propuesta de lectura-escritura tiene ejes y contornos netamente definidos, habitualmente despreciados y vilipendiados por el llamado pensamiento débil. En primer lugar, la historia, especialmente la de la América Latina, aunque también la de otras revoluciones antimperialistas y anticapitalistas del mundo subdesarrollado. En segundo lugar, la ideología. En tercer lugar, el sujeto y, finalmente, en cuarto pero no en último lugar, la revolución. El collage de Dalton, repleto de retazos polifónicos, no tiene entonces nada que ver con la fragmentación entrecortada de un videoclip posmoderno, donde las partes coexisten yuxtapuestas sin un sentido articulador que las ordene y les otorgue una dirección” (Kohan, 2009). 